\title{
HISTOLOGICAL STUDY OF FRESH VERSUS FROZEN SEMITENDINOUS MUSCLE TENDON ALLOGRAFTS
}

\author{
Alexandre Carneiro Bitar, Luiz Augusto Ubirajara Santos, Alberto Tesconi \\ Croci, João Alberto Ramos Maradei Pereira, Edgard N. França Bisneto, Arlete \\ Mazzini Miranda Giovani, Claudia Regina G. C. M. Oliveira
}

doi: $10.1590 / \mathbf{S 1 8 0 7 - 5 9 3 2 2 0 1 0 0 0 0 3 0 0 0 1 0}$

Bitar AC, Santos LAU, Croci AT, Pereira JARM, França-Bisneto EN, Giovani AMM, Oliveira CRGCM. Histological study of fresh versus frozen semitendinous muscle tendon allografts. Clinics. 2010;65(3):297-303.

OBJECTIVE: The purpose of this study was to histologically analyze allografts from cadaveric semitendinous muscle after cryopreservation at $-80^{\circ} \mathrm{C}$ in comparison to a control group kept at only $-4^{\circ} \mathrm{C}$ to test the hypothesis that the histological characteristics of the tissue are maintained when the tendons are kept at lower temperatures.

METHODS: In a tissue bank, 10 semitendinous tendons from 10 cadavers were frozen at $-80^{\circ} \mathrm{C}$ as a storage method for tissue preservation. They were kept frozen for 40 days, and then a histological study was carried out. Another 10 tendon samples were analyzed while still "fresh".

RESULTS: There was no histological difference between the fresh and frozen samples in relation to seven variables.

CONCLUSIONS: Semitendinous muscle tendon allografts can be submitted to cryopreservation at $-80^{\circ} \mathrm{C}$ without suffering histological modifications.

KEYWORDS: Cryopreservation; Tissue banks; Histology; Tendons; Tissue transplantation.

\section{INTRODUCTION}

The use of allogenic tissues is growing in orthopedic practice, as is the number of studies on methods for processing, sterilization and cryopreservation that interfere as little as possible with the original physiological properties of the tissues. ${ }^{1}$

The literature compares allografts with autologous grafts in knee ligament reconstruction surgery, with little difference in clinical results. ${ }^{2,3}$ However, compared with autologous transplants, allografts do have some advantages. For example, they do not increase morbidity for the donor, they require a shorter surgery time, and they are available without restriction on size and morphology. They are best indicated for multiple ligament reconstructions, revision

Institute of Orthopedics and Traumatology, Hospital das Clinicas da Faculdade de Medicina da Universidade de São Paulo - São Paulo/SP, Brazil. Email: banco.tecidos.iot@hcnet.usp.br

Tel.: $55113069.6776 / 8101$

Received for publicaiton on November 23, 2009

Accepted for publication on December 03, 2009 surgeries, and patella baja. ${ }^{4-7}$ In ligament reconstruction surgeries, the possibility exists of an immune response from the recipient tunnel enlargement, and delayed incorporation of the allograft. ${ }^{3}$ The risk of disease transmission and the potential for immunogenicity are the major disadvantages of allografts, ${ }^{8}$ but these complications can be controlled. ${ }^{9,10}$

Grafts can be processed and stored in different ways, and the preparation techniques have the potential to change the initial resistance and mechanical properties of the graft prior to implantation. ${ }^{11}$ Theoretically, any method that promotes cell debridement of the collagenous matrix should reduce the antigenicity of the tissue. However, it is essential that the extraction does not destroy the collagen matrix, which could result in alteration of the biomechanical properties of the graft. ${ }^{11,12}$

Although there are studies on the biomechanical behavior of cryopreserved tendons, ${ }^{13}$ the literature does not address the histological changes of the tissue at $-80^{\circ} \mathrm{C}$.

The purpose of this study was to histologically analyze allografts from cadaveric semitendinous muscle after cryopreservation at $-80^{\circ} \mathrm{C}$ in comparison to a control group 
kept at only $-4{ }^{\circ} \mathrm{C}$ to test the hypothesis that the histological characteristics of the tissue are maintained when the tendons are kept at lower temperatures.

\section{METHODS}

Twenty semitendinous muscle tendons (10 from the left limb and 10 from the right) from 10 cadavers were used in this study. The cadavers, all aged 20 to 40 years old, were obtained from the local mortuary service and were kept for up to 48 hours at $-4^{\circ} \mathrm{C}$. None of the cadavers demonstrated neoplasias, infections, previous surgeries, collagen diseases, or degenerative diseases, and none had received corticosteroid therapy or chemotherapy that might have altered the tendinous structures. The causes of death are listed in Table 1.

Table 1- Characteristics and cause of death among the cadavers studied

\begin{tabular}{lccl}
\hline No. & Sex & Age (years) & Cause of death \\
\hline 1 & Male & 38 & Heart failure \\
2 & Female & 34 & Obstructive acute abdomen \\
3 & Male & 39 & Stroke \\
4 & Male & 33 & Cirrhosis \\
5 & Male & 27 & Heart failure \\
6 & Male & 40 & Pulmonary embolism \\
7 & Male & 31 & Heart failure \\
8 & Male & 36 & Heart failure \\
9 & Female & 29 & Cirrhosis \\
10 & Male & 38 & Pulmonary embolism \\
\hline Mean & & 34.5 & - \\
\hline
\end{tabular}

The tendons of the semitendinous muscle were removed after dissection of the skin and subcutaneous tissue with a tendon extractor commonly used in surgeries for knee ligament reconstruction. The technique was standardized: $5-\mathrm{cm}$ portions of tendon were removed from an area $3 \mathrm{~cm}$ away from the insertion site, a region where there is no transition of muscle or bone, only tendon tissue.

The samples were soaked in $0.9 \%$ sodium chloride (saline) solution to prevent dehydration or alteration of the tissue architecture. Of the 20 tendons obtained, 10 were prepared for microscopic analysis the next day (Group A), and the remaining 10 (Group B) were sent to the tissue bank for cryopreservation for 40 days. Each cadaver had a tendon in Group A and a tendon in Group B. The determination of groups according to the sides (right and left) was random.

The 10 tendons in Group A were fixed for 24 hours in a $10 \%$ formalin solution. The 10 tendons for the tissue bank (Group B) were packaged in sealed 0.5 micrometer polyethylene and nylon bags, with triple protection, in accordance with international standards of the European Association of Tissue Banks (EATB) and the American Association of Tissue Banks (AATB),${ }^{14}$ and were kept cryopreserved at $-80^{\circ} \mathrm{C}$ in an electric vertical ultrafreezer (model SANYO MDF U3086S, Sanyo Electric Co. Ltd.) equipped with a $\mathrm{CO}_{2}$ backup, a warning system and temperature monitoring via satellite, producing a printed report of temperature levels every six hours.

After 40 days of cryopreservation, the tendons in Group B were thawed by immersion in $0.9 \% \mathrm{NaCl}$ isotonic saline solution for 30 minutes at room temperature and fixed in formalin solution for a further 24 hours. As with Group A, which was already fixed in formalin, these samples were stained using hematoxylin and eosin and cut longitudinally and transversely to produce $2 \mathrm{~mm}$-thick pieces. The analysis of the histological slides was always done by the same pathologist and in random order.

The cellular and structural components of each piece were analyzed using an optical microscope. The cellular components were investigated for the presence of inflammatory reaction (cell infiltration and edema) and fibroblast proliferation. The histological architecture, orientation of the fibers, quality of the matrix and presence or absence of angiogenesis were structurally evaluated.

The Fischer exact and chi-square tests were used for statistical analysis. Differences with $\mathrm{p} \leq 0.05$ were considered significant.

\section{RESULTS}

The data from the histological study of the tendons fixed in formalin and the cryopreserved tendons are listed in Table 2. Table 3 lists the histological features for the total samples of fresh and frozen tendons, some of which are illustrated in Figures 1 to 4 . The Fischer exact and chi square tests did not show statistical differences ( $p>0.3$ for all variables); this shows that for all variables, there was no tissue modification due to freezing.

\section{DISCUSSION}

Grafts are used in various procedures in different branches of orthopedics, including ligament reconstruction. The literature shows the importance of the use of allografts in knee surgery, especially in revision surgeries, multiple ligament reconstructions and, more recently, surgery for primary reconstruction of the anterior cruciate ligament (ACL) in active ${ }^{3,15}$ patients and in those aged over 40 years. ${ }^{16}$

The first report of the use of allografts in humans dates 
Table 2 - Histological analysis of fresh and frozen semitendinous tendons

\begin{tabular}{|c|c|c|c|c|c|c|c|}
\hline \multicolumn{8}{|l|}{ Fresh tendons } \\
\hline Sample piece & Architecture & Fiber orientation & Matrix & Cell infiltration & $\begin{array}{l}\text { Fibroblast } \\
\text { proliferation }\end{array}$ & Edema & Vascularization \\
\hline 1 & Preserved & Preserved & Preserved & Absent & Absent & Absent & Absent \\
\hline 2 & Preserved & Preserved & Preserved & Present & Present & Present & Present \\
\hline 3 & Preserved & Preserved & Preserved & Present & Present & Present & Present \\
\hline 4 & Preserved & Preserved & Preserved & Present & Present & Present & Present \\
\hline 5 & Preserved & Preserved & $\begin{array}{l}\text { Hyaline } \\
\text { Degeneration }\end{array}$ & Absent & Absent & Present & Absent \\
\hline 6 & Preserved & Preserved & Preserved & Present & Present & Present & Present \\
\hline 7 & Preserved & Preserved & $\begin{array}{l}\text { Focal } \\
\text { Degeneration }\end{array}$ & Present & Present & Present & Present \\
\hline 8 & Preserved & Disorganized & Degenerated & Present & Present & Present & Present \\
\hline 9 & Preserved & Disorganized & Preserved & Present & Present & Present & Present \\
\hline 10 & Preserved & Preserved & Preserved & Absent & Absent & Present & Present \\
\hline \multicolumn{8}{|c|}{ Frozen tendons } \\
\hline Sample piece & Architecture & Fiber orientation & Matrix & Cell infiltration & $\begin{array}{l}\text { Fibroblast } \\
\text { proliferation }\end{array}$ & Edema & Vascularization \\
\hline 1 & Preserved & Disorganized & Degenerated & Present & Present & Present & Present \\
\hline 2 & Preserved & Preserved & $\begin{array}{l}\text { Necrotic } \\
\text { degeneration }\end{array}$ & Absent & Absent & Present & Present \\
\hline 3 & Preserved & Disorganized & Preserved & Absent & Absent & Present & Present \\
\hline 4 & Preserved & Preserved & Preserved & Absent & Absent & Present & Present \\
\hline 5 & Preserved & $\begin{array}{l}\text { Focal } \\
\text { Disorganization }\end{array}$ & Preserved & Absent & Absent & Present & Present \\
\hline 6 & Preserved & Preserved & Preserved & Present & Present & Present & Present \\
\hline 7 & Preserved & Preserved & Preserved & Absent & Absent & Present & Present \\
\hline 8 & Preserved & Disorganized & Preserved & Present & Present & Present & Present \\
\hline 9 & Preserved & Disorganized & Degenerated & Present & Absent & Absent & Present \\
\hline 10 & Preserved & Disorganized & Preserved & Absent & Absent & Absent & Present \\
\hline
\end{tabular}

back to $1881 .{ }^{17}$ The first tissue bank of bone grafts was created in 1940 in the United States, and the initial clinical results were published in 1942 by Inclan. ${ }^{18}$ Since then, a series of regulations and studies has emerged relating to the use of grafts in orthopedic practice. ${ }^{19}$ In our institute, the Tissue Bank has been in operation since 1999 and is governed by local legislation. ${ }^{20}$

There have been at least 11 clinical studies comparing the use of auto and allografts in the reconstruction of the ACL. ${ }^{2,3}$ Most of these show little difference between the two techniques with respect to long-term results. However, there has been no prospective randomized study, and the comparison methods (scores), types of graft, as well as methods of preparing and fixing the graft are highly variable. Furthermore, most studies use the patellar tendon graft; therefore, it may not be possible to generalize the conclusions of these studies to the flexor tendon.
Macey ${ }^{21}$ was the first to use the semitendinosus tendon for reconstruction of the intra-articular knee. The practice of using this free graft has increased since the 1990s and is currently compared with the patellar tendon as the first option for autografting in primary surgeries for ACL reconstruction. ${ }^{15}$

Some authors, such as Lawhorn and Howel122, suggest the use of allografts without a bone plug because of the potential for slower incorporation of the bone due to immunogenicity and smaller cross-sectional area of transplants with bone plugs. Hadjicostas et al., ${ }^{23}$ compared the histological features of the patellar tendon and semitendinosus and gracilis tendons in cadavers. Differences were found in the relationship between fibrils/interstitium (20 to 30\% higher in the flexor) and density of fibroblasts (35 to 50\%). It was noted that there is an advantage of these grafts with regard to the renovation and integration of the patellar tendon. 
Currently, tendon allografts are used in knee surgeries, in elbow ligament reconstructions, and for revisions of the acromioclavicular joint. ${ }^{24}$ In our medical service, allografts are used mainly in knee surgeries, ACL reconstruction, multiple ligament reconstructions, ligament surgery in skeletally immature patients and with double bundle

Table 3 - Statistical analysis of the histological results

\begin{tabular}{|c|c|c|c|}
\hline & Fresh & Frozen & Total \\
\hline Histological architecture & \multicolumn{3}{|c|}{$\mathrm{p}=1.0($ Fisher exact test $)$} \\
\hline Preserved & 10 & 10 & 20 \\
\hline Not preserved & 0 & 0 & 0 \\
\hline Total & 10 & 10 & 20 \\
\hline Fiber orientation & \multicolumn{3}{|c|}{$\mathrm{p}=0.35$ (Fisher exact test) } \\
\hline Preserved & 8 & 5 & 13 \\
\hline Disorganized & 2 & 5 & 7 \\
\hline Total & 10 & 10 & 20 \\
\hline Matrix & \multicolumn{3}{|c|}{$\mathrm{p}=1$ (Fisher exact test $)$} \\
\hline Preserved & 7 & 7 & 14 \\
\hline Degenerated & 3 & 3 & 6 \\
\hline Total & 10 & 10 & 20 \\
\hline Cell infiltration & \multicolumn{3}{|c|}{$\mathrm{p}=0.37$ (Fisher exact test $)$} \\
\hline Present & 7 & 4 & 11 \\
\hline Absent & 3 & 6 & 9 \\
\hline Total & 10 & 10 & 20 \\
\hline Fibroblast proliferation & \multicolumn{3}{|c|}{$\mathrm{p}=0.18($ Chi squared test $)$} \\
\hline Present & 7 & 3 & 11 \\
\hline Absent & 3 & 6 & 9 \\
\hline Total & 10 & 10 & 20 \\
\hline Edema & \multicolumn{3}{|c|}{$\mathrm{p}=1.0$ (Fisher exact test $)$} \\
\hline Present & 8 & 8 & 16 \\
\hline Absent & 2 & 2 & 4 \\
\hline Total & 10 & 10 & 20 \\
\hline Vascularization & \multicolumn{3}{|c|}{$\mathrm{p}=0.47$ (Fisher exact test) } \\
\hline Present & 8 & 10 & 18 \\
\hline Absent & 2 & 0 & 2 \\
\hline Total & 10 & 10 & 20 \\
\hline
\end{tabular}

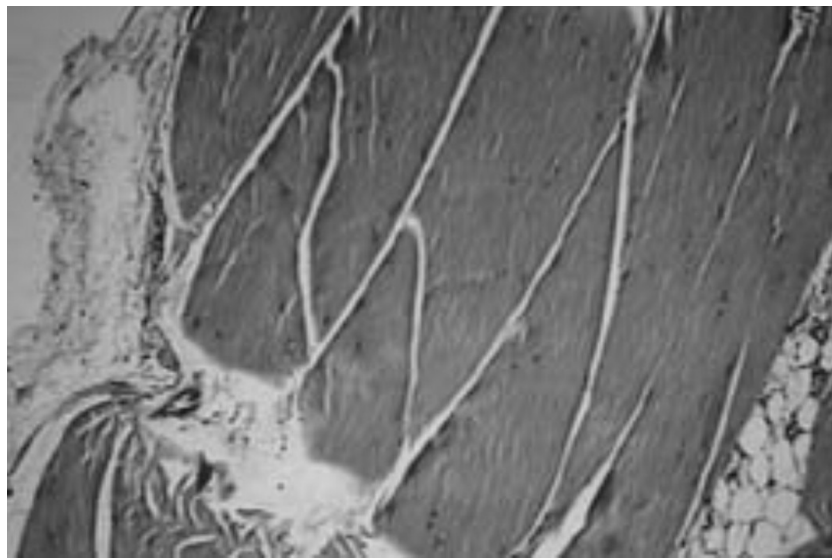

Figure 1 - Histological aspect of sample \#3, a fresh tendon (hematoxylineosin, $40 \mathrm{X})$. reconstruction. Other studies with patellar tendon grafts and Achilles tendon grafts have been carried out by our institute, analyzing the biomechanical aspects and comparing the same methods of preparation, with no statistically significant differences. ${ }^{25,26}$

We did not make a distinction as to sex at the time of

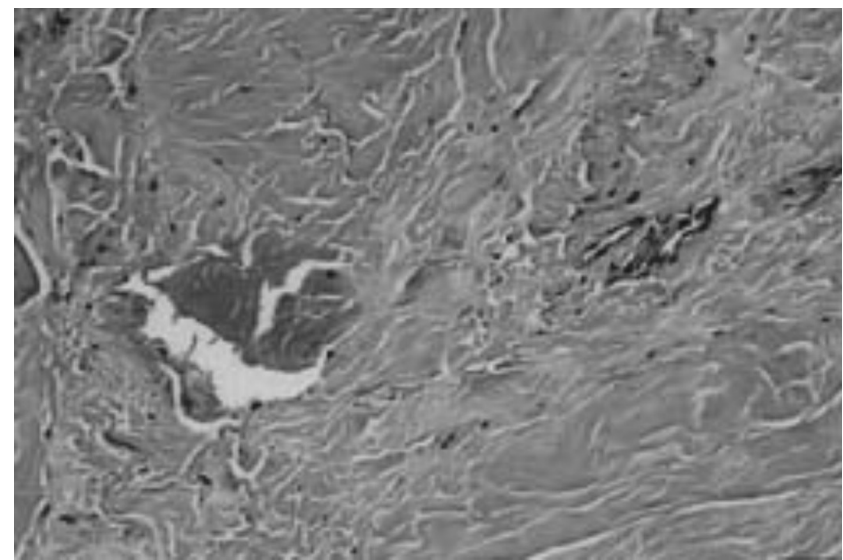

Figure 2 - Histological aspect of sample \#8, a frozen tendon: degenerated matrix and intact vascularization (hematoxylin-eosin, $40 \mathrm{X}$ ).

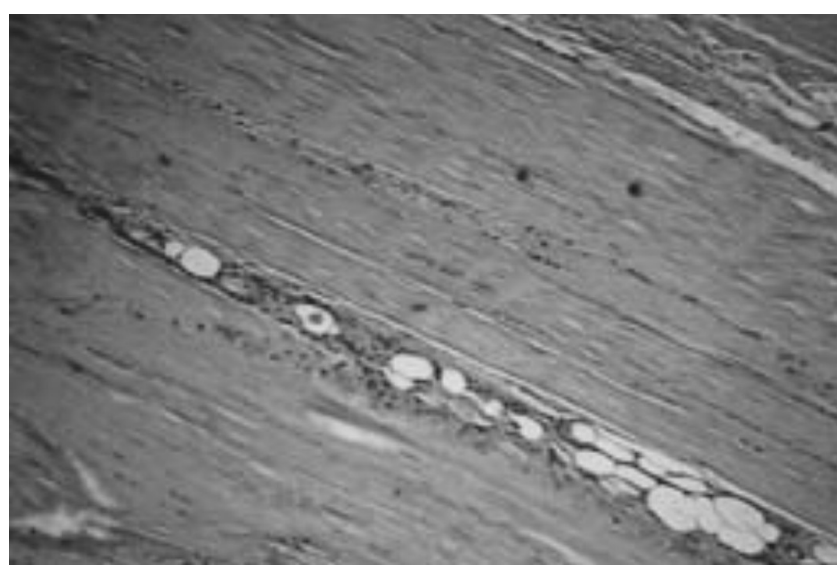

Figure 3 - Histological aspect of sample \#1, a frozen tendon: fibroblastic proliferation and degenerated matrix (hematoxylin-eosin, $100 \mathrm{X}$ ).

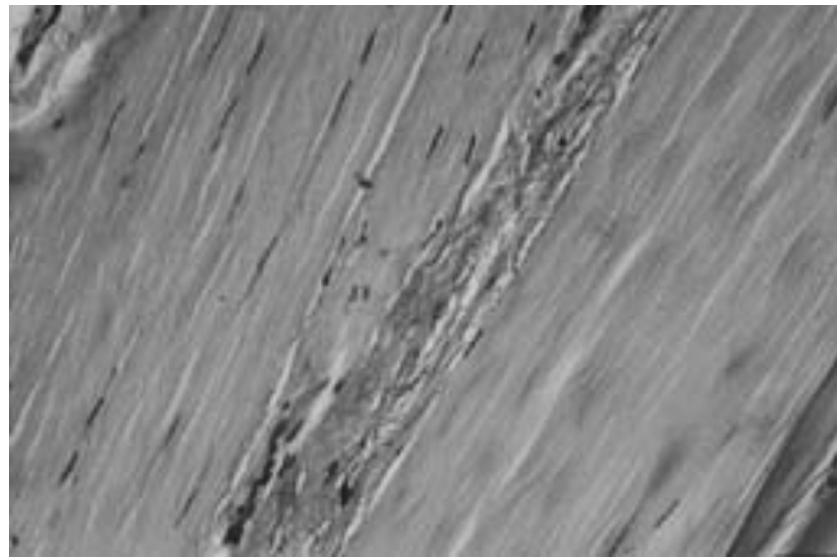

Figure 4 - Histological aspect of sample \#2, a frozen tendon: focal necrosis and degenerated matrix (hematoxylin-eosin, $100 \mathrm{X}$ ). 
selection of the cadavers included in our sample. Like the work of Hadjicostas et al., ${ }^{23}$ we included bodies of both sexes. Limiting the age of the cadavers in this study served to remove the degenerative effects that can be seen after age 40 as a result of tissue aging, and also to reduce the risk of injuries and disruptions to which aging individuals are naturally predisposed. The patients included in the study by Hadjicostas et al. ${ }^{23}$ had a higher mean age (56.6 years) than our sample. In fact, age and sex appear to have little effect on the composition of samples for tissue donation. ${ }^{27}$

The increased frequency of the use of allografts in traumato-orthopedics requires the adoption of storage techniques that interfere as little as possible in the quality of the parts. ${ }^{17,19}$ Allografts can be stored in different ways; they can be chilled in residential mechanical freezers at temperatures of $+2^{\circ} \mathrm{C}$ to $-4^{\circ} \mathrm{C}$ for up to five days. In freezers with temperatures of $-20^{\circ} \mathrm{C}$ to $-40^{\circ} \mathrm{C}$, they can be stored for up to six months. ${ }^{14}$ At these temperatures, the enzymes present in the tissue are still active and can destroy the tissue. Therefore, storage periods of longer than a few months are not recommended. The methods of sterilization used at low temperatures are effective against fungi and do not seem to change the mechanical characteristics of the grafts. The period of 40 days chosen in this study coincides with the period of incubation necessary for microbiological investigations for bacteria and fungi. ${ }^{19}$ The deep-freezing process enables storage for up to five years ${ }^{19}$, and this is the method we use in our service.

Many services prefer to carry out the manipulation of tissues under aseptic conditions from acquisition through clinical use, and the samples are discarded when microbiological assays show positive bacterial cultures (20 to $30 \%){ }^{28}$ Sterilization methods, therefore, are not completely safe. They can alter the biomechanical characteristics of tissues or fail to penetrate tissue layers, resulting in the protection of microorganisms rather than their destruction. Irradiation with gamma rays is the most common method of sterilization. ${ }^{12,}{ }^{29}$ However, to achieve safer sterilization in frozen tissues, high-dose irradiation is necessary, which can alter the biomechanical properties of the tissue. Also, the sterilization effectiveness against viruses is low. ${ }^{19}$ Ethylene oxide sterilization requires strict control of the levels of waste gas in contact with the allograft and is no longer used by tissue banks, due to the possibility of toxic effects for the recipient (dissolution of the graft and articular inflammatory reactions). ${ }^{19}$

The processing techniques used in the preparation and preservation of grafts have been questioned as potentially altering the initial resistance and mechanical properties of the graft prior to implantation. ${ }^{11}$ Two studies carried out in Brazil address the biomechanical properties of patellar ${ }^{25}$ and calcaneus ${ }^{26}$ tendons of cadavers with the same preparation method as that used in our study, comparing fresh and cryopreserved allografts. They found no differences. A study on metric measurements and attachment levels of the medial patellofemoral ligament shows this to be a distinct structure. ${ }^{30}$

Although there have been studies on the biomechanical behavior of tendons, ${ }^{13}$ the literature does not address histological changes of tendons cryopreserved at $-80^{\circ} \mathrm{C}$ under aseptic conditions. During cryopreservation at $-80^{\circ} \mathrm{C}$, the destruction of the allograft enzyme appears to be minimal and at least one enzyme, collagenase, which can destroy the tissue, is inactive. ${ }^{31}$ Furthermore, with cryopreservation there is no intracellular free water, which is thought to be necessary for enzymatic activity, bacterial proliferation and lipid oxidation. ${ }^{32,33}$ Lipid oxidation inside the tissues induces apoptosis and inhibits cell differentiation; such oxidation can be minimized or avoided with cryopreservation at temperatures of at least $-70^{\circ} \mathrm{C} .{ }^{33}$

The literature refers to histological changes due to cryopreservation only in cartilage ${ }^{34}$ (one of the most commonly used grafts in surgical practice),${ }^{34}$ concluding that during freezing, the vitality of the cells is threatened. Other injuries may also occur, such as the formation of extracellular ice crystals, intracellular ice nucleation, collapse of the matrix, and breakage of intercellular bridges. In our study, the histological study of one tendon (not cartilage) was carried out, and none of these histological phenomena were observed with cryopreservation at $-80^{\circ} \mathrm{C}$.

Freezing with liquid nitrogen at $-179^{\circ} \mathrm{C}$ has also been used as a storage method with similar results but higher cost. ${ }^{28}$ Another widespread storage method is lyophilization. Cryopreservation and lyophilization have been related to a reduction in allograft antigenicity. ${ }^{6}$ The use of chilled saline solution is not a guaranteed method because the stock can only be kept safely for short periods. ${ }^{28}$ Treatment with paraformaldehyde and fixation with glutaraldehyde are no longer recommended because of the toxicity of these solutions to the recipient tissue.

Fibroblasts play a key role in the regeneration of tendinous tissues, regardless of the location. Papandrea et al.,. ${ }^{35}$ reported evidence of regeneration of the medial flexor tendon by means of an ultrasonographic study two months after autologous graft collection in ligament reconstruction surgery. It was demonstrated that graft thickness, width and cross-sectional area were higher than the preoperative measurements. After six months, the tendons continued to demonstrate high width measurements. The thickness and width then started to decrease, and, after two years, they presented sizes similar to typical semitendinosus tendons, showing that a process of regeneration does in fact occur. 
Ferretti et al. ${ }^{36}$ carried out a histological study with three patients undergoing review surgery (after 6, 24 and 26 months), using the medial flexors as the initial graft. Biopsy specimens taken after the six-month period still showed histological immaturity, with fibroblast proliferation but irregularity in the organization of the collagen fibers. However, after two years, both tendons showed welloriented fibers, similar to the tendons of patients who had not been operated on. Pufe et al., ${ }^{37}$ noted that the density of fibroblasts negatively influences the mechanical properties of the tendons. Hadjicostas et al.,. ${ }^{23}$ speculated that a high concentration of fibroblasts in the medial flexor tendons could lead to a better healing response of the tendons. In our sample, the freezing process did not interfere with fibroblast proliferation or the structure of the tendon.

Vasculature also appeared to be preserved after freezing of the tendons in the present work. Hadjicostas et al., ${ }^{23}$ showed a higher concentration of vessels in the flexor tendons when compared to the patellar tendons, but no correlation was observed with the other variables. There is some controversy, however, concerning the influence of angiogenesis in the process of tendon healing, as previous studies show that the density of blood vessels adversely affects the biomechanical properties of the tendons. ${ }^{38}$

Graf et al., ${ }^{39}$ studied the effects of freezing the tendon through histological, biochemical and biomechanical analyses of the patellar tendon after reconstruction of the ACL in rabbits, and did not observe any significant difference in comparison with the control group. The only investigation in the literature comparing the histological features of fresh versus frozen tendons in cadavers, to our knowledge, is the present study.

We believe that other variables, such as storage time ${ }^{11}$, should be examined in future works. The quantification of histological variables through cell counts and histomorphometry could make the analysis of the effect of freezing more objective. Special staining for collagen and glycogen or even other variables could also deepen the histological analysis. In the future, we believe that these data will serve to improve the use of these tissues for transplant allografts, with the possibility of lower tissue reaction, lower inflammation rates and perhaps lesser effects of rejection, increasing the resistance of allografts and making their use in surgical practice more feasible.

\section{CONCLUSION}

Tendons of the semitendinosus muscle of human cadavers, when subjected to cryopreservation at $-80^{\circ} \mathrm{C}$, retain their histological architecture, orientation of fibers, matrix, cellular infiltration, fibroblast proliferation, swelling and blood, with no histological changes when compared to fresh tendons.

\section{REFERENCES}

1. Nutton RW, McLean I, Melville E. Tendon allografts in knee ligament surgery. J R Coll Surg Edinb. 1999;44:236-40.

2. Chang SK, Egami DK, Shaieb MD, Kan DM, Richardson AB. Anterior cruciate ligament reconstruction: allograft versus autograft. Arthroscopy. 2003;19:453-62.

3. Marrale J, Morrissey MC, Haddad FS. A literature review of autograft and allograft anterior cruciate ligament reconstruction. Knee Surg Sports Traumatol Arthrosc. 2007;15:690-704.

4. Flahiff CM, Brooks AT, Hollis JM, Vander Schilden JL, Nicholas RW. Biomechanical analysis of patellar tendon allografts as a function of donor age. Am J Sports Med. 1995;23:354-8.

5. Jackson DW, Corsetti J, Simon TM. Biologic incorporation of allograft anterior cruciate ligament replacements. Clin Orthop. 1996;324:126-33.

6. Jackson DW, Windler GE, Simon TM. Intraarticular reaction associated with the use of freeze-dried, ethylene oxide-sterilized bone-patella tendon-bone allografts in the reconstruction of the anterior cruciate ligament. Am J Sports Med. 1990;18:1-10; discussion 10-1.

7. Levitt RL, Malinin T, Posada A, Michalow A. Reconstruction of anterior cruciate ligaments with bone-patellar tendon-bone and achilles tendon allografts. Clin Orthop Relat Res. 1994;303:67-78.
8. Barrios RH, Leyes M, Amillo S, Oteiza C. Bacterial contamination of allografts. Acta Orthop Belg. 1994;60:293-5.

9. Albert A, Leemrijse T, Druez V, Delloye C, Cornu O. Are bone autografts still necessary in 2006? A three-year retrospective study of bone grafting. Acta Orthop Belg. 2006;72:734-40.

10. Urabe K, Itoman M, Toyama Y, Yanase Y, Iwamoto Y, Ohgushi H, et al. Current trends in bone grafting and the issue of banked bone allografts based on the fourth nationwide survey of bone grafting status from 2000 to 2004. J Orthop Sci. 2007;12:520-5.

11. Sterling JC, Meyers MC, Calvo RD. Allograft failure in cruciate ligament reconstruction. Follow-up evaluation of eighteen patients. Am J Sports Med. 1995;23:173-8.

12. Salamon A, Hámori J. Development of collagenous fibres in autologous and preserved homologous tendon grafts. Acta Morphol Acad Sci Hung. 1976;24:11-22.

13. Pearsall AW 4th, Hollis JM, Russell GV Jr, Scheer Z. A biomechanical comparison of three lower extremity tendons for ligamentous reconstruction about the knee. Arthroscopy. 2003;19:1091-6.

14. American Association of Tissue Banks. Standards for Tissue Banking. $10^{\text {th }}$ ed. McLean: American Association of Tissue Banks; 2005. 
15. Sherman $\mathrm{OH}, \mathrm{Banffy} \mathrm{MB}$. Anterior cruciate ligament reconstruction: which graft is best? Arthroscopy. 2004;20:974-80.

16. Barrett G, Stokes D, White M. Anterior cruciate ligament reconstruction in patients older than 40 years: allograft versus autograft patellar tendon. Am J Sports Med. 2005;33:1505-12.

17. Malinin TI. Allografts for the reconstruction of the cruciate ligaments of the knee: procurement, sterilization and storage. Sports Med Arthroscopy. 1993;1:31-41.

18. Inclan A. The use of preserved bone graft in orthopaedic surgery. J Bone Joint Surg Am. 1942;24:81-96. Disponível em: http://www.ejbjs.org/cgi/ reprint/24/1/81. Acessado em 2008 (09 out)

19. Vangsness CT Jr, Garcia IA, Mills CR, Kainer MA, Roberts MR, Moore TM. Allograft transplantation in the knee: tissue regulation, procurement, processing, and sterilization. Am J Sports Med. 2003;31:474-81.

20. Amatuzzi MM, Croci AT, Giovani AMM, Santos LAU. Banco de tecidos: estruturação e normatização. [Tissue bank: structure and organization]. Rev Bras Ortop. 2000;35:165-72.

21. Macey HB. A new operative procedure for the repair of ruptured cruciate ligament of the knee joint. Surg Gynecol Obstet. 1939;69:108-9.

22. Lawhorn KW, Howell SM. Scientific justification and technique for anterior cruciate ligament reconstruction using autogenous and allogenic soft-tissue grafts. Orthop Clin North Am. 2003;34:19-30.

23. Hadjicostas PT, Soucacos PN, Paessler HH, Koleganova N, Berger I. Morphologic and histologic comparison between the patella and hamstring tendons grafts: a descriptive and anatomic study. Arthroscopy. 2007;23:751-6.

24. Costic RS, Labriola JE, Rodosky MW, Debski RE. Biomechanical rationale for development of anatomical reconstructions of coracoclavicular ligaments after complete acromioclavicular joint dislocations. Am J Sports Med. 2004;32:1929-36.

25. Giovani AM, Croci AT, Oliveira CR, Filippi RZ, Santos LA, Maragni GG, et al. Comparative study of cryopreserved bone tissue and tissue preserved in a $98 \%$ glycerol solution. Clinics. 2006;61:565-70.

26. Reiff RBM, Croci AT, Bolliger Neto R, Pereira CAM. Estudo comparativo de propriedades biomecânicas da porção central do tendão calcâneo congelado e a fresco. [Comparative study on biomechanical properties of the central portion of frozen and fresh calcaneus tendon]. Acta Ortop Bras. 2007;15:6-8.

27. Pietrzak WS, Woodell-May J. The composition of human cortical allograft bone derived from FDA/AATB-screened donors. J Craniofac Surg. 2005;16:579-85.
28. Zimmerman MC, Contiliano JH, Parsons JR, Prewett A, Billotti J. The biomechanics and histopatology of chemically processed patellar tendon allografts for anterior cruciate ligament replacement. Am J Sports Med. 1994;22:378-86

29. Jackson DW, Grood ES, Wilcox P, Butler DL, Simon TM, Holden JP. The effects of processing techniques on the mechanical properties of bone-anterior cruciate ligament-bone allografts. An experimental study in goats. Am J Sports Med. 1988;16:101-5.

30. Aragão JA, Reis FP, de Vasconcelos DP, Feitosa VL, Nunes MA. Metric measurements and attachment levels of the medial patellofemoral ligament: an anatomical study in cadavers. Clinics. 2008;63:541-4.

31. Tomford W. Transmission of disease through musculoskeletal transplantation. Portland Bone Symposium. Portland: Oregon Health Sciences University; 1997.

32. Galea G, Kearney JN. Clinical effectiveness of processed and unprocessed bone. Transfus Med. 2005;15:165-74

33. Laitinen M, Kivikari R, Hirn M. Lipid oxidation may reduce the quality of a fresh-frozen bone allograft. Is the approved storage temperature too high? Acta Orthop. 2006;77:418-21.

34. Schachar NS, McGann LE. Investigations of low-temperature storage of articular cartilage for transplantation. Clin Orthop Relat Res. 1986;14650.

35. Papandrea P, Vulpiani MC, Ferretti A, Conteduca F. Regeneration of the semitendinosus tendon harvested for anterior cruciate ligament reconstruction. Evaluation using ultrasonography. Am J Sports Med. 2000;28:556-61.

36. Ferretti A, Conteduca F, Morelli F, Masi V. Regeneration of the semitendinosus tendon after its use in anterior cruciate ligament reconstruction: a histologic study of three cases. Am J Sports Med. 2002;30:204-7.

37. Pufe T, Petersen WJ, Mentlein R, Tillman BN. The role of vasculature and angiogenesis for the pathogenesis of degenerative tendons disease. Scand J Med Sci Sports. 2005;15:211-22.

38. Yoshikawa T, Tohyama H, Katsura T, Kondo E, Kotani Y, Matsumoto $\mathrm{H}$, et al. Effects of local administration of vascular endothelial growth factor on mechanical characteristics of the semitendinosus tendon graft after anterior cruciate ligament reconstruction in sheep. Am J Sports Med. 2006;34:1918-25.

39. Graf BK, Fujisaki K, Vanderby R Jr, Vailas AC. The effect of in situ freezing on rabbit patellar tendon. A histologic, biochemical, and biomechanical analysis. Am J Sports Med. 1992;20:401-5. 
